\title{
Knowledge, Attitude, and Practice of Induced Abortion among Adolescent Female Students in Selected Secondary Schools in Moshi Municipality, Kilimanjaro Region, Northern Tanzania.
}

\author{
Frank Albert Kimbwereza \\ Kilimanjaro Christian Medical University College \\ Jesca Sael Nkya \\ Kilimanjaro Christian Medical University College \\ Andrew Lelo Mboya \\ Kilimanjaro Christian Medical University College \\ Bernard Njau ( $\square$ biesein2007@gmail.com ) \\ Kilimanjaro Christian Medical Centre
}

\section{Research}

Keywords: Induced abortion, Knowledge, Attitude, Practice, Adolescent, Individual-level factors

Posted Date: May 4th, 2020

DOI: https://doi.org/10.21203/rs.3.rs-25006/v1

License: (1) (1) This work is licensed under a Creative Commons Attribution 4.0 International License.

Read Full License 


\section{Abstract}

\section{Background:}

Unsafe abortion is a significant problem for adolescent female students and among a leading cause of maternal mortality globally. In Tanzania, abortion is illegal, unless under medical emergencies, thus putting female students with an unwanted pregnancy at higher risk of unsafe abortion, with severe consequences, including death. The study aimed to determine the level of knowledge, attitude, and practices of induced abortion among adolescent girls in selected secondary schools in Moshi municipality, Kilimanjaro region.

\section{Method:}

A descriptive cross-sectional study was conducted among 342 secondary school girls aged 15-19 years from April-June 2019. Eligible participants were selected by a multistage sampling technique. Semistructured self-administered questionnaires were used for data collection. Data were entered and analyzed using SPSS software.

\section{Results:}

The mean age of respondents were 16.7(SD 3.7), and 50.6\% ( $n=173 / 342$; mean knowledge score $=38.9$ $\pm 1.4)$ had a low level of knowledge on induced abortion. More than half, 55.8\% ( $n=191 / 342 ;$ mean attitude score $=18.9 \pm 1.9)$ had a negative attitude towards induced abortion. Only, $5.6 \%(n=19 / 342)$ of respondents had induced abortion from unwanted pregnancy before. The two main reasons of induced abortion were to finish school (26.3\%), and fear of parents' reactions $(26.3 \%)$.

\section{Conclusion:}

Respondents had poor knowledge of induced abortion and a negative attitude towards induced abortion. Poor knowledge was because of a lack of understanding of the standard definition of induced abortion. Cultural and religious factors mostly influence the negative attitude towards induced abortion. A low proportion of sexually experienced respondents reported unwanted pregnancies and induced abortion. The main reasons for induced abortion are fear of termination from the education system and fear of parents' reactions. Effective adolescent's reproductive and sexual health intervention is warranted to prevent unwanted pregnancies in this setting.

\section{Plain English Summary}

Unsafe abortion is a leading cause of death worldwide, including adolescent female students. In this study we sought to understand the level of knowledge, attitude, and practices of unsafe abortion among adolescent female students in selected secondary schools in Moshi municipality in Kilimanjaro region, northern Tanzania. A total of 342 secondary school girls aged 15-19 years were approached and agreed to participate in the study from April-June 2019. Of the 322 respondents, almost half, $50.6 \%(n=$ 
173/342) had poor knowledge on unsafe abortion. Also, 55.8\% $(n=191 / 342)$ had a negative attitude towards unsafe abortion. Only, 5.6\% $(n=19 / 322)$ of respondents had unsafe abortion from unwanted pregnancy before. The two main reasons for unsafe abortion were to finish school (26.3\%), and fear of parents' reactions $(26.3 \%)$.

In conclusion, respondents had poor knowledge of unsafe abortion and a negative attitude towards unsafe abortion. Poor knowledge was because of a lack of understanding of the meaning of unsafe abortion. Cultural and religious factors mostly influence the negative attitude towards unsafe abortion. These findings will help in addressing the problem of unwanted pregnancies and unsafe abortion among adolescent female students in Moshi municipality in Kilimanjaro region, northern Tanzania.

\section{Background}

Induced abortion is the intentional termination of pregnancy before 20 weeks of gestation or fetus born with weight less than 500 grams, that cannot live independently [1]. World Health Organization (WHO) classifies induced abortion into; safe abortion which is done by the trained health care provider and at appropriate gestational age with services recommended by WHO (i.e., post-abortion care), less safe abortion in which it is done by a health care provider using methods not recommended by WHO, and unsafe abortion, which is done by an untrained person using traditional methods such as local herbs [ 1 , 2].

It is estimated that 25.1 million induced abortions, with $97 \%$ occurred in low and middle-income countries (LMICs), annually between 2010 and 2014 [3]. In the same period, the highest number of abortions in the Caribbean was estimated to be 59 per 1000 women, and the lowest number was 17 per 1000 women of reproductive age (i.e., 14 to 49 years) in Northern America [3]. In Africa, 59.0\% of all unsafe abortions occur in women aged less than 25 years [1,2]. The number of induced abortion are relatively growing in developing countries compared to developed countries, in 2014 there was 37 abortion per 1000 women aged 15 to 44 years in developing countries compared to 27 per 1000 in developed countries [3].

Post-abortion care (PAC) services are provided in settings where abortion is legal or illegal, in many hospitals globally. PAC services aim to reduce both mortality and morbidity arising from incomplete and or unsafe abortions. The PAC services include emergency treatments using manual vacuum aspirations (MVA), or dilatation and curettage (D \& C) techniques. Also testing for sexually transmitted infections (STI), and provision of family planning and contraceptives [4].

Abortion is illegal in Tanzania and carries a heavy jail sentence unless termination of pregnancy is under a medical emergency [5-7]. The country, however, is one of the LMICS with high abortion rates approximated at 36 per 1000 women under 25 years old. The highest rates are reported in Lake Zone (51 per 1000) and the lowest rates in Zanzibar (11 per 1000) among women aged 15-44 years [6, 7]. 
In Tanzania, adolescent girls with unwanted pregnancy face social consequences, such as being expelled out of the education system, as school dropouts play a common practice following regulation, which does not allow pregnant girls to continue with their studies [5-7]. Two main reasons most adolescent girls undergo unsafe abortion are because of restrictive abortion law [6-9], and fear of education disruption [5]. Because of the unfriendly environment, most abortions are conducted under unsafe, covert situations, putting adolescent girls at high risk of maternal mortality rates caused by severe bleeding, sepsis, and even death [9-11].

For Tanzania, to achieve one of the Sustainable Development Goals (SDGs) that aim to reduce global maternal mortality ratio to less than 70 per 100,000 live births by 2030, it is imperative to address the issue of unsafe abortions among adolescent girls [12]. This study aimed at determining the knowledge, attitude, and practice towards abortion among adolescent girls aged 15 to 19 years in selected secondary schools in Northern Tanzania. The study findings would provide information to the existing evidence on knowledge, attitude, and practice on induced abortion and recommendations for appropriate interventions that will ensure universal access to sexual and reproductive health-care services among adolescent girls in this study setting.

\section{Methods}

\section{Study design}

This was a descriptive cross-sectional study conducted from April to June 2019 to assess the knowledge, attitude, and practice of adolescent girls towards induced abortion in Northern Tanzania.

\section{Study Area}

This study was conducted in the Moshi Urban district, which is one of the seven districts of the Kilimanjaro Region of Tanzania. Moshi Urban district is bordered to the North, South, and East by the Moshi Rural district and to the West by the Hai district. According to the 2012 Tanzania national census, the population of the Moshi urban district was 184,292. Moshi town is among the tourist circuit of Northern Tanzania and home to the highest mountain in Africa-Mt. Kilimanjaro. Moshi urban district has 23 secondary schools, including 14 public and 9 private schools. Out of the 23 schools, one is a boy's school and the remaining 22 are mixed-sex schools (i.e., boys and girls), with a total number of 2538 female students.

\section{Study Population}

The study population was adolescent girls aged 15-19 years old from four selected secondary schools in Moshi town. 


\section{Eligibility Criteria}

All eligible female students aged 15-19 years old were included in this study. Female students who did not provide consent, or where absent from school on the day of data collection where excluded from this study.

\section{Sample size determination}

To determine the sample size with a $95 \%$ level of confidence, a $5 \%$ margin of error, and a proportion of $50.0 \%$ (for unknown prevalence), we used the formula for a descriptive cross-sectional study where the target is less than 10,000 . The minimum sample size including the non-response rate was 422 respondents.

\section{Sampling Technique}

The multistage sampling technique was used to select 422 study respondents from 4 mixed-sex secondary schools.

In stage one, four out of 22 secondary schools, were selected using a simple random sampling method by lottery procedure. In stage two, students were stratified by their classes (i.e., forms 1 to 6 ) to make different stratum in each school. In stage three, the required numbers of students were selected from each stratum proportional to their size using a systematic random sampling technique.

\section{Study Variables}

The dependent variables in this study were knowledge of induced abortion, attitude towards induced abortion, and practice of induced abortion. Independent variables include socio-demographic characteristics, and sexual behavior of respondents.

\section{Measurements}

\section{Knowledge scores}

The level of knowledge on induced abortion was measured using 10 questions (e.g., induced abortion is abortion done by oneself). The expected response 6-point Likert scale was ( $1=$ strongly disagree, to $6=$ strongly agree). The reliability scale was Cronbach's alpha $=.61$. Responses in each domain were added to create an overall knowledge score. The mean score was used to categorize the level of knowledge into good knowledge ( $>$ mean score), and poor knowledge ( $</=$ mean score). 
Attitude towards induced abortion was measured using 6 questions (e.g., It is a sin to induce abortion). The expected response 6 -point Likert scale was ( $1=$ strongly disagree, to $6=$ strongly agree). The reliability scale was Cronbach's alpha $=.62$. Responses in each domain were added to create an overall attitude score. The mean attitude score was categorized into a positive attitude ( $>$ mean score), and a negative attitude $(</=$ mean score $)$.

\section{Data collection method}

A pre-tested, semi-structured questionnaire adopted from Ethiopia [13], and adapted to fit the study objectives, to assess knowledge on induced abortion, attitude towards induced abortion, and practice of induced abortion from study respondents. The self-administered questionnaire was conducted in English, which is the language used as the medium in teaching in secondary schools in Tanzania.

\section{Data analysis}

The filled questionnaires were cross-checked daily for accuracy, completeness, uniformity, and then double entered in a database. Data were analyzed using Statistical Package for Social Science (SPSS) for Windows Version 20.0 statistical software. Descriptive analysis was estimated as frequency and proportions. A Chi-square test was used to compare proportions between categorical variables. A p-value of .05 or less was considered to be significant.

\section{Ethical Consideration}

Research and ethical clearance were obtained from the Kilimanjaro Christian Medical University College Ethics Committee. Permission to conduct the study was sought from the local education officer and headmasters of the four selected schools. Written consent was obtained after potential respondents were informed of the study's aims, and their participation is voluntary and was free to withdraw from the study. All parents/guardians for respondents below 18 years were allowed to withhold their child from the study.

\section{Results}

Out of the 424 respondents recruited in this study, 342 (80.7\% response rate) participated in this study. Forty-six respondents refused to participate in this study, 6 participants did not return their questionnaires, and 30 questionnaires were discarded because of incompleteness and inconsistency of data.

\section{Characteristics Of The Participants}

The age range and the mean age (standard deviation) of the study respondents were 15 to 19 years and $16.7 \pm 3.7$ respectively. More than two-thirds, $66.1 \%$ of respondents were aged 15 to 17 years, Christians (81.0\%), forms 1 to 4 (70.2\%), living at home (61.4\%), and Chagga tribe (52.3\%). 
Table 1

Sociodemographic characteristics of the respondents $(\mathrm{N}=342)$.

\begin{tabular}{|ll|}
\hline Variables & \multicolumn{1}{|c|}{$\begin{array}{l}\text { Frequency (\%) } \\
\mathbf{N}=342\end{array}$} \\
\hline Age group & (years) \\
\hline $15-17$ & $226(66.1)$ \\
\hline $18-19$ & $116(33.9)$ \\
\hline Mean Age 16.7 \pm 3.7 \\
\hline Religion \\
\hline Christian & $277(81)$ \\
\hline Muslim & $65(19)$ \\
\hline Class & \\
\hline Forms 1 to 4 & $240(70.2)$ \\
\hline Forms 5 to 6 & $102(29.8)$ \\
\hline Ethnicity & \\
\hline Chagaa tribe & $179(52.3)$ \\
\hline Other tribes & $163(47.7)$ \\
\hline Living arrangement \\
\hline At hostel & $132(38.6)$ \\
\hline At home & $210(61.4)$ \\
\hline
\end{tabular}

\section{Knowledge Of The Induced Abortion}

Almost half, $50.6 \%(173 / 342)$ had a poor knowledge compared to $49.4 \%$ who had good knowledge of induced abortion. The mean knowledge score was $38.9 \pm 1.4$. The majority $(94.7 \%)$ of the respondents knew that induced abortion can lead to death, while more than a quarter $(25.1 \%)$ of respondents was unaware that induced abortion can be done alone by an individual [Table 2]. 
Table 2

Respondents' knowledge of induced abortion ( $\mathrm{N}=342)$.

\begin{tabular}{|l|l|}
\hline Statements on knowledge of induced abortion & $\begin{array}{c}\text { Agreeing } \\
\text { response } \\
\text { frequency (\%) }\end{array}$ \\
\hline Induced abortion is an abortion done by myself. & $\mathbf{N} \mathbf{3 4 2}$ \\
\hline Induced abortion is an abortion done in the hospital by untrained person. & $86(25.1)$ \\
\hline Induced abortion is an abortion done by taking local herbs. & $124(36.3)$ \\
\hline Induced abortion is an abortion done by a trained doctor in his house. & $190(55.5)$ \\
\hline Induced abortion is an abortion done by an elderly woman in the community. & $125(36.5)$ \\
\hline Induced abortion can lead to infection. & $135(39.5)$ \\
\hline Induced abortion can lead to excessive bleeding. & $288(84.2)$ \\
\hline Induced abortion can lead to death. & $315(92.1)$ \\
\hline $\begin{array}{l}\text { Induced abortion can be performed through surgical instruments/modern } \\
\text { medicines. }\end{array}$ & $322(94.2)$ \\
\hline Taking local herbs can induce abortion. & $299(87.4)$ \\
\hline
\end{tabular}

The most common source of abortion among respondents was friends $(42.6 \%)$, followed by mass media (39.2\%), books/pamphlets/posters (7.5\%), health care providers $(7.2 \%)$, and other sources (3.5\%). There was a statistically significant association between the living arrangement of the respondents and their level of knowledge of induced abortion. Respondents staying at the hostel were more likely to have good knowledge compared to those who are staying at home [Table 3]. 
Table 3

Association between socio demographics and knowledge of induced abortion $(n=342)$.

\begin{tabular}{|llll|}
\hline Socio demographic characteristics & \multicolumn{2}{l}{$\begin{array}{l}\text { Knowledge of induced abortion } \\
\text { Frequency (\%) }\end{array}$} & P-value \\
\cline { 2 - 4 } & Good & Poor & Total \\
\hline Age group (years) $\mathrm{P}=0.13$ & & & \\
\hline $15-17$ & $105(46.5)$ & $121(53.5)$ & $226(100)$ \\
\hline $18-19$ & $64(55.2)$ & $52(44.8)$ & $116(100)$ \\
\hline Religion $P=0.43$ & & & \\
\hline Christian & $143(51.6)$ & $134(48.4)$ & $277(100)$ \\
\hline Muslim & $35(53.8)$ & $30(46.2)$ & $65(100)$ \\
\hline Class $P=0.12$ & & & \\
\hline Forms 1 to 4 & $112(46.7)$ & $128(53.3)$ & $240(100)$ \\
\hline Forms 5 to 6 & $57(55.9)$ & $45(44.1)$ & $102(100)$ \\
\hline Living arrangement $P=<0.009 *$ & & & \\
\hline At hostel & & & \\
\hline At home & $77(58.3)$ & $55(41.7)$ & $132(100)$ \\
\hline * $P<0.01$ & $92(43.8)$ & $118(56.2)$ & $210(100)$ \\
\hline
\end{tabular}

\section{Attitude Towards Induced Abortion}

More than half, $55.8 \%,(191 / 342)$ of the respondents had a negative attitude towards induced abortion compared to $44.2 \%$ who had a positive attitude. The mean attitude score was $18.9 \pm 1.9$.

The majority, $303 / 342$ (88.6\%) of respondents agreed that it's a sin to induce abortion, and only $12 \%$ would abort if pregnant, or encourage a friend to abort [Table 4]. 
Table 4

Attitude towards induced abortion $(\mathrm{N}=342)$.

\begin{tabular}{|ll|}
\hline Statements of attitude towards induced abortion & $\begin{array}{l}\text { Agreeing response frequency (\%) } \\
\mathbf{N}=\mathbf{3 4 2}\end{array}$ \\
\hline It's a sin to induce abortion. & $303(88.6)$ \\
\hline Induced abortion can kill because of its complications. & $305(89.2)$ \\
\hline Family planning methods can prevent unwanted pregnancy. & $307(89.8)$ \\
\hline Unwanted pregnancy should be aborted. & $56(16.4)$ \\
\hline I would undergo an abort if pregnant. & $41(12)$ \\
\hline I would encourage my friend to abort if pregnant. & $41(12)$ \\
\hline
\end{tabular}

There was no statistically significant association between sociodemographic characteristics of the respondents and their attitude towards induced abortion [data not shown].

\section{The Practice Of Induced Abortion}

Out of 342 respondents, 52 (15.2\%) reported being sexually experienced, and 28/52 (53.8\%) of sexually experienced respondents used family planning. A very small proportion of respondents, 19/342 (5.6\%), reported being pregnant before and had an abortion. Table 5 below presents the respondents' practice of induced abortion. Of 19 respondents who had an abortion, 5 (26.3\%) had an abortion at 15 years or below, and the remaining 14 (73.7\%) had an abortion at age 16 years or above. More than half, $(52.7 \%)$ of respondents had one previous abortion, compared with $47.4 \%$ who had 2 or more. The majority, $16 / 19(84.2 \%)$ of abortions were done in a private health facility, $10.5 \%$ at home, and $5.3 \%$ in a public health facility. The majority, $89.5 \%$ (17/19) of abortions were performed by a health professional, and only 2 were performed by traditional healers. Nine of the respondents $(47.2 \%)$ had their abortion carried out with surgical instruments, while eight of the respondents (42.1\%) used modern medicines, and only two (10.5\%) of respondents used local herbs to induce their abortion. More than a quarter, $5 / 19(26.3 \%)$ of respondents induced abortion to finish school, followed by fear of parents' reactions (26.3\%), lack of money to support the child, $(21.1 \%)$, rejection by partner and family, $(15.8 \%)$, and shame in society (10.5\%). More than two-thirds, $68.4 \%$ (13/19) of respondents experienced complications, compared with $31.6 \%$ who did not. Of those 13 respondents who experienced complications post-abortion, $61.5 \%$ reported excessive bleeding, followed by abdominal pains (30.8\%), and nausea/vomiting $(7.7 \%)$. 
Table 5

Respondents' practice of induced abortion $(n=19)$.

\begin{tabular}{|c|c|}
\hline \multirow[t]{2}{*}{ Variables } & Frequency (\%) \\
\hline & $N=19$ \\
\hline \multicolumn{2}{|l|}{ Age at first abortion } \\
\hline 15 year or below & $5(26.3)$ \\
\hline 16 years or above & 14(73.7) \\
\hline \multicolumn{2}{|l|}{ Number of previous abortion(s) } \\
\hline 1 & $10(52.6)$ \\
\hline 2 or more & $9(47.4)$ \\
\hline \multicolumn{2}{|l|}{ Place where abortion was done } \\
\hline Public health facility & $1(5.3)$ \\
\hline Private health facility & 16(84.2) \\
\hline Home & $2(10.5)$ \\
\hline \multicolumn{2}{|l|}{ Person who performed abortion } \\
\hline Health professional & 17(89.5) \\
\hline Traditional healer & $2(10.5)$ \\
\hline \multicolumn{2}{|l|}{ Material used to induce abortion } \\
\hline Surgical instruments & $9(47.4)$ \\
\hline Modern medicine & $8(42.1)$ \\
\hline Local herbs & $2(10.5)$ \\
\hline \multicolumn{2}{|l|}{ Reasons for inducing abortion } \\
\hline To finish school & $5(26.3)$ \\
\hline Fear of parents & $5(26.3)$ \\
\hline Lack of money to support the child & $4(21.1)$ \\
\hline Rejection by partner and family & $3(15.8)$ \\
\hline Shame in society & $2(10.5)$ \\
\hline \multicolumn{2}{|l|}{ Experienced any complications } \\
\hline Yes & $13(68.4)$ \\
\hline No & $6(31.6)$ \\
\hline
\end{tabular}

Page $11 / 18$ 


\begin{tabular}{|ll|}
\hline Variables & $\begin{array}{l}\text { Frequency (\%) } \\
\mathbf{N}=19\end{array}$ \\
\hline Type of complications $(\mathbf{n}=13)$ & \\
\hline Excessive bleeding & $8(61.5)$ \\
\hline Abdominal pains & $4(30.8)$ \\
\hline Nausea /vomiting & $1(7.7)$ \\
\hline
\end{tabular}

\section{Discussion}

This study aimed to determine the knowledge, attitude, and practice towards induced abortion among adolescent girls in a selected secondary school in Moshi municipal. This study has shown that almost half of the respondents have a poor knowledge of induced abortion. This observation is contrary to similar studies done in Nigeria [11], and Goma [14], in which $88.3 \%$ and $61.3 \%$ respectively of respondents had good knowledge of induced abortion. A similar result of poor knowledge of induced abortion was observed in a study among female students in different settings in Ethiopia [13, 15]. The observed variations might be explained because of methodological differences in the categorization of the knowledge scores used in each study. Therefore the role of misclassification bias could not be excluded. An alternative explanation could be the difference in the source's information about induced abortion information in different study settings $[11,13,14]$. In the current study, respondents who were living in a hostel were more likely to have good knowledge of induced abortion compared to those who stay at home. This observation corroborates with the study finding that most respondents first heard about abortion from their friends [11]. Respondents who reside at the hostel may have more time together and share more health information, including induced abortion. Future intervention to increase the level of knowledge of induced abortion in this setting should emphasize on the standard definition of an induced abortion according to the WHO [1, 2], and target female students who are residing at home.

More than half of the respondents in this study had a negative attitude towards induced abortion. This proportion is lower than what was reported in different studies done in Ethiopia [13, 15], in which the majority of respondents had a negative attitude towards induced abortion. The most important explanatory factor to the current observation could be explained by religious belief. The majority of respondents in this study agreed that induced abortion was a sin against God. Most respondents in this study were either Christians or Muslims-both doctrines do not advocate abortion [11, 13, 14]. This observation, however, should be taken with caution, because there was no statistically significant association between the religion of respondents and their attitude towards induced abortion. However, it is well documented in behavior studies that religion and cultural factors have a very strong influence on an individual's attitude [16].

Although this study did not ask about the legalization of abortion in the country, which is a key determinant in the reduction of the burden associated with unsafe abortion [1, 2]. low proportions of 
study respondents agreed that unwanted pregnancies should be aborted, or whether they would abort if pregnant, or encourage their friends to have an abortion if pregnant. Similar findings were reported from similar studies in other settings in Africa $[11,14,15]$. Countries such as Tanzania, with restive abortion law $[5,6,8,9]$, need to integrate and develop national strategies, and programs, such as Adolescent Sexual and Reproductive Health (ASRH) interventions, which will empower adolescents to universal access for family planning, reproductive health information and education in secondary schools in Tanzania $[12,17]$.

In this study, the prevalence of induced abortion was very low (5.5\%). This result concurs with findings from a study in Brazil [18], but high compared to findings reported in Ethiopia (2.5\%), and Nigeria (2\%), respectively [11, 13]. However, the current finding is very low compared to studies done in Uganda [19], Nigeria (Cadmus and Owoaje 2011), and Ethiopia [20], reporting high abortion rates among adolescents. Religious and cultural factors, restrictive laws on induced abortion, awareness campaigns on risk of induced abortion, abstinence and condom use among adolescents may explain the observed low prevalence of unwanted pregnancies in these settings $[11,13,14]$. Given the fact that a significant number of the adolescent in this study reported being sexually experienced, with low use of contraception, it is important to undertake community-based qualitative studies to explore abortion experiences among female students in this study setting.

Most respondents reported their first abortion at a young age (16 years or above), although the majority, had aborted only once. This alarming observation highlights the presence of induced abortion from unwanted pregnancy among female students in secondary schools in this study setting. Unsurprisingly, this study revealed that most of the induced abortions were done by health professionals working in private for-profit health facilities. Very few respondents attended a traditional healer for induced abortion. This observation concurs with findings from studies done in SSA countries [7, 13]. The health system in Tanzania is categorized as public (government-owned), private (not-for-profit owned/or private for-profit owed). Government-owned health facilities are supervised directly by the Ministry of Health, Community Development, Gender, Elderly and Children (MoHCDGEC), and follows government regulations[21], including the restive abortion law, making difficult for adolescent girls with unwanted pregnancy accessing PAC. Hence, the only option for adolescent girls to undergo an induced abortion is the privatefor-profit health facilities [5-7].

Based on the above observation, this study showed that most respondents who undergone an induced abortion, surgical instruments, or modern medicines were used. This observation concurs with a finding reported from a similar study conducted in Zanzibar, where adolescent girls, used blend of herbs, and modern drugs to ensure that the induced abortion does not fail [7].

In this study, the two main reasons mentioned by most respondents who undergone induced abortion was to finish their education and fear of parents' reactions. These results concur with findings from a study conducted in Ethiopia $[13,22]$. This observation may be attributable to the restive laws on unwanted pregnancy among female students, which lead to termination from the education system $[5,6]$. 
To avoid having their educational aspirations terminated, most female students opt for induced abortion $[14,22]$. To reduce the problem of induced abortion because of fear of termination from the education system, it is imperative to have supportive intervention in this setting, which will enroll female students with unwanted pregnancies to continue with their studies after delivery.

Fear of parents' reactions arises from the fact that in most African societies, it is a taboo, and a sign of disrespect to discuss sexual matters with parents. Also, based on religious belief, becoming pregnant before marriage, or induce abortion is seen as an abomination [11]. In this study setting, interventionists of ASRH programs need to integrate religious leaders and parents in the design, and implementation of effective interventions to reduce unwanted pregnancy among adolescent girls in secondary schools. According to Babalola et al. parents' awareness of their adolescents' social networks contributes to influencing their attitudes about sexual behavior, such as abstinence [23].

Finally, the most common complication post-abortion mentioned by respondents who had undergone induced abortion was excessive bleeding, followed by abdominal pains. This observation corroborates with the high proportion of respondents in the current study who mention excessive bleeding among the leading complication associated with induced abortion. This finding concurs with results from studies conducted in different settings in Africa $[10,11,19,20,22]$. It is a well documented in the peer-reviewed literature regarding induced abortion, that excessive bleeding is the main cause of both morbidity and mortality, which impact on the health of adolescent girls with unwanted pregnancies worldwide $[1,2,8]$.

\section{Study Limitations}

The study limitations that should be taken into consideration include the following.

First, this is cross-sectional study design, hence it is unable to demonstrate the causal-effect relationships reported in this study. Second, the generalizability of the study findings is limited to the study setting only. Third, the study respondents were asked very sensitive issues such as their practices of induced abortion, which is illegal in Tanzania hence the possibility of response bias can not be excluded and may influence the low proportion of induced abortion reported in this study. Finally, the validity of the study findings may be affected by the moderate internal reliability of the scales used to assess the level of knowledge $(\mathrm{a}=.61)$ and attitude $(\mathrm{a}=.62)$ towards induced abortion.

\section{Conclusion}

In conclusion, the study respondents had poor knowledge of induced abortion and negative attitudes towards induced abortion. Poor knowledge was because of respondents' lack of understanding of the standard definition of inducing abortion according to the WHO. Negative attitude towards induced abortion is mostly influenced by cultural and religious factors, bearing in mind that abortion is illegal in Tanzania, and both Christianity and Muslim doctrines do not support abortion. Despite the low proportion of respondents who reported being sexually experienced, family planning use is very low leading to 
unwanted pregnancies and induced abortion. Fear of termination from the education system and fear of parents' reactions are the main reasons why adolescent girls with unwanted pregnancies opt for induced abortion. Effective ARSH interventions, which will integrate religious leaders and parents may be beneficial to adolescent girls attending secondary schools in this study setting.

\section{Abbreviations}

DHS: Development health survey; LMICS:Low and Middle-Income Country; MMR:Maternal Mortality Rate; MoHDGEC:Ministry of Health, Development, Gender, Elderly and Children and Social Welfare; WHO:World Health Organization.

\section{Declarations}

\section{Acknowledgments}

The authors acknowledge the research assistants who assisted in the data collection and participants who participated in the study.

\section{Author's contributions】}

FAK, JSN, and ALM contributed to the conception and design of the study, data collection, analysis, interpretation, and manuscript writing under the supervision of BN. All authors read the draft of the manuscript, provided feedback, and approved the final manuscript.

\section{Funding}

No funds were received for this study.

\section{Availability of data and materials}

The datasets generated and analyzed during this study are not publicly available but may be available from the corresponding author upon reasonable request and with permission from the Kilimanjaro Christian Medical University College.

\section{Ethics approval and consent to participate}

\section{This study was conducted following the Helsinki Declaration. This study protocol was submitted and received approvals from the Kilimanjaro Christian Medical}




\section{College Research Ethics Committee. Informed written}

consent was sought from eligible respondents before data collection. Also, respondents were informed of the study objectives, confidentiality, and that participation was voluntary, and their right to withdraw from the study at any time.

\section{Consent for publication}

Not applicable.

\section{Competing interests}

The authors declare that they have no competing interests.

\section{Author Details}

${ }^{1}$ Kilimanjaro Christian Medical University College,Kilimanjaro, Tanzania. ${ }^{2}$ Community Health Department, Kilimanjaro Christian Medical Centre, Kilimanjaro, Tanzania.

\section{References}

1. WHO: Unsafe Abortion: Global and Regional Estimates of the Incidence of Unsafe Abortion and Associated Mortality in 2003. In., Fifth ed. Geneva: WHO; 2007.

2. WHO: Facts on induced abortion worldwide in brief. Guttmacher Institute. In. Geneva; 2011.

3. Ganatra B, Gerdts C, Rossier C, Johnson BR, Jr., Tuncalp O, Assifi A, Sedgh G, Singh S, Bankole A, Popinchalk A, et al: Global, regional, and subregional classification of abortions by safety, 2010-14: estimates from a Bayesian hierarchical model. Lancet 2017, 390(10110):2372-2381.

4. Corbett MR, Turner KL: Essential Elements of Postabortion Care: Origins, Evolution, and Future Directions. International Family Planning Perspectives 2003, 29(3):1-6.

5. Nkata $\mathrm{HH}$, Barros $\mathrm{H}$, Nyamhanga $\mathrm{T}$ : Unsafe induced abortion, a case study of secondary school girls in Igunga district-Tanzania. European Journal of Public Health 2017, 27.

6. Keogh SC, Kimaro G, Muganyizi P, Philbin J, Kahwa A, Ngadaya E, Bankole A: Incidence of Induced Abortion and Post-Abortion Care in Tanzania. PLoS One 2015, 10(9):e0133933.

7. Norris A, Harrington BJ, Grossman D, Hemed M, Hindin MJ: Abortion experiences among Zanzibari women: a chain-referral sampling study. Reproductive Health 2016, 13:1-23. 
8. Johnson BR, Mishra V, Francheska LA, Khoslaa R, Ganatraa B: A global database of abortion laws, policies, health standards, and guidelines.Bulletin of the World Health Organisation 2017, 95(7):542544.

9. Sorensen BL, Elsass P, Nielsen BB, Massawe S, Nyakina J, Rasch V: Substandard emergency obstetric care-a confidential inquiry into maternal deaths at a regional hospital in Tanzania. Tropical Medicine and International Health 2010 15(8):894-900.

10. Lin TB, Hsieh MF, ., Hou CY, Hsueh LY, Chang HP, Tseng TY: Long-term physical health consequences of abortion in Taiwan, 2000 to 2013. A nationwide retrospective cohort study. Medicine 2018, 97(31):e11785.(31):e11785.

11. Abiola AO, Oke OA, Balogun MR, Olatona FA, Adegbesan-Omilabu MA: Knowledge, attitude, and practice of abortion among female students of two public senior secondary schools in Lagos Mainland Local Government Area, Lagos State. Journal of Clinical Sciences 2016, 13(2):82.

12. United Nations Sustainable Goals(SDGs) [https://www.un.org/sustainabledevelopment/sustainabledevelopment-goals/]

13. Yaecob R, Abera D, Meleko A: Knowledge, Attitude and Practice towards Induced Abortion and Associated Factors among Female students in Yebu Secondary School, Jimma zone, South West Ethiopia.Global Journal of Reproductive Medicine 2018, 5(2):1-8.

14. Paluku JL, Kalisoke S, Wandabwa J, Kiondo P: Knowledge and attitudes about induced abortions among female youths attending Naguru Teenage Information and Health Centre, Kampala, Uganda. Journal of Public Health and Epidemiology 2013, 5(4):178-185.

15. Gelaye A, Nigussie K, Mekonen T: Magnitude and risk factors of abortion among regular female students in Wolaita Sodo University, Ethiopia. BMC Women's Health 2014, 14(50).

16. Champion VL, Skinner CS: The Health Belief Model. In: Health Behaviour \& Health Education: Theory, Research, and Practice. Volume 4th Edition,20082008., ed. Edited by Glanz K et al.: Jossey-Bass, San Francisco, Calif, USA; 2008: 45-65.

17. Renju J, Andrew B, Nyalali K, Kishamawe C, Kato C, Changalucha J, Obasi A: A process evaluation of the scale-up of a youth-friendly health services initiative in northern Tanzania. Journal of International AIDS Society 2010, 13(32.).

18. Correia DS, Cavalcante JC, Maia EM: Induced abortion: risk factors for adolescent female students, a Brazilian study.Scientific World Journal 2009, 9:1374-1381.

19. Sully EA, Atuyambe L, Bukenya J, Whitehead HS, Blades N, Bankole A: Estimating abortion incidence among adolescents and differences in postabortion care by age: a cross-sectional study of postabortion care patients in Uganda. Contraception 2018, 98(6):510-516.

20. Lentiro K, Gebru T, Worku A, Asfaw A, Gebremariam T, Tesfaye A: Risk factors of induced abortion among preparatory school students in Guraghe zone, Southern region, Ethiopia: a cross-sectional study. BMC Women's Health 2019, 19(1):115.

21. United Republic of Tanzania: the United Republic of Tanzania, Ministry of Health, Community Development, Gender, Elderly and Children, National AIDS Control Programme: Health Sector HIV and 
AIDS Strategic Plan (HSHSP-IV) 2017-2022. 2017:1-84.

22. Cadmus EO, Owoaje ET: KNOWLEDGE ABOUT COMPLICATIONS AND PRACTICE OF ABORTION AMONG FEMALE UNDERGRADUATES IN THE UNIVERSITY OF IBADAN, NIGERIA. Annals of Ibadan Postgraduate Medicine 2011, 9(1):19-23.

23. Babalola $\mathrm{S}$, Vondrasek $\mathrm{C}$, Brown J: Factors affecting sexual practices in West Africa: a positive deviant approach. In: APHA Annual Conference, 21-25 October 2001, Atlanta, Georgia.; 2001. 